Egyptian

Orthodontic Journal

\title{
ASSESSMENT OF SELF-ASSEMBLING PEPTIDE P-11-4 IN THE TREATMENT OF WHITE SPOT LESIONS AFTER ORTHODONTIC TREATMENT
}

Fatma Abdel Aziz ${ }^{1}$, Tarek H. Marei ${ }^{1}$, Magda A. Elmalt ${ }^{2}$ ABSTRACT:

The aim of the current study was to investigate the effect of commercially available Curodont on enamel surface with white spot lesions after orthodontic treatment. $\mathcal{A}$ total of 14 teeth with white spot lesions in orthodontically treated subjects aged 12 to 22 years were enrolled in this clinical study. All participants recently finished their treatment with fixed orthodontic appliances in the Department of Orthodontics at the Faculty of Dentistry for girls, Al-Azhar University. Digital periapical x-ray was taken before and after three months of curodont application. Comparisons between the measures of the baseline and post treatment images were calculated to determine the radiodenisty change (mineral content change) before and after treatment. Paired $t$-test was used to compare between enamel mineral content change before and after treatment. Also saliva was collected to measure the change of pH of saliva after three and six months, using saliva - check buffer Testing. The results showed that there was a statistically significant increase in enamel mineral content after treatment. The mean \pm standard deviation values of percentage increase were $25.7 \pm 16.1 \%$. Conclusion: Curodont proved to be an effective remineralizing agent for treatment of enamel WSLs that occurred after orthodontic treatment.

1- Assistant Professor, Orthodontic Department -Faculty of Dental Medicine for girls Al-Azhar University

2- Lecturer, Pedodontic Department -Faculty of Dental Medicine for girls Al-Azhar University 
Egyptian

Orthodontic Journal

\section{INTRODUCTION}

The formation of dental caries is a dynamic process based on the misbalance between demineralization of enamel, i.e., $\mathrm{Ca}$ and $\mathrm{P}$ ion loss from the hydroxyapatite prisms, and its mineralization via diffusion of the same ions from saliva back into the enamel nanostructures ${ }^{(1)}$

White spot lesions (WSLs) are defined as a "subsurface enamel porosity from carious demineralization" that presents as "a milky white opacity when located on smooth surfaces."(2) Since fixed orthodontic appliances were introduced, WSLs have become a particular clinical problem that can be attributed to the difficulties in performing oral hygiene procedures on bonded dental arches and the prolonged plaque accumulation on tooth surfaces. ${ }^{(3)}$ Despite many attempts at comprehensive prophylaxis, the prevalence of WSLs remains as high as $61 \%$ when debonding. ${ }^{(4)}$ It is generally believed that these lesions will recover through natural remineralization with saliva once the orthodontic appliances have been removed and oral hygiene is restored. ${ }^{(5)}$ However, the removal of stagnant plaque alone is not enough to achieve complete repair of WSLs, and some spots secondary to debonding can last from 5 to 12 years ${ }^{(6)}$

White-spot lesions can occur during and following fixed orthodontic treatment ${ }^{(7)}$.

There is an increase in the incidence and severity of white enamel lesions, and significant increase in the prevalence on the cervical and middle thirds of the crowns of the maxillary anterior teeth. ${ }^{(8)}$

Changes in tooth structure due to extrinsic factors have been widely investigated. Whereas the material losses (absolute erosions) have been carefully characterized, only minor attention has been devoted to the investigation of tooth surface change during erosion and demineralization. The kinetic roughening of a surface is the process that takes place when material is removed from or added to the surface. ${ }^{(9)}$

Enamel is composed of crystalline calcium phosphate of $96 \%$ mineral with the remaining $4 \%$ consisting of organic components and water. The organic content consists of breakdown products of major 
Egyptian

Orthodontic Journal

enamel protein amelogenin. The mature enamel is acellular and does not regenerate itself unlike other biomineralized tissues such as bone and dentin. To replace enamel, dentistry has formulated artificial materials that mimic the hardness of enamel but replacing enamel with artificial substitutes. But none of these materials could mimic all the physical, mechanical, and aesthetic properties of enamel. Recently scientists have shown much interest in the direction of synthesizing artificial enamel. Thorough understanding of structure and pattern of ameloblast gene products, control of protein self-assembly and simultaneous hydroxyapatite crystallization allows to design biomimetic approaches to create synthetic enamel. Now there is transition of shifting emphasis from traditional synthetic biomaterials toward biological materials. An advance in tissue engineering methods paves a way for enamel regeneration, rapid progress being made in biomimetic synthesis and cellular enamel formation for tooth repair. ${ }^{(10)}$

A systematic review indicated a lack of reliable evidence to support the effectiveness of remineralizing agents for the treatment of post orthodontic WSLs. ${ }^{(11)}$ The management of white-spot lesions remains a challenge, especially during and after fixed orthodontic treatment. ${ }^{(7)}$

Remineralization of white-spot lesions and carious lesions may be possible with a variety of currently available agents containing fluoride, bioavailable calcium and phosphate, and casein phosphopeptide in-amorphous calcium phosphate. ${ }^{(12)}$

Recent developments in tissue engineering, material sciences and stem cell research offer considerable potential to dental therapies. Peptide treatment for early caries lesion is the area of current research. Peptide treatment significantly increases net mineral gain due to a combined effect of increased mineral gain and inhibition of mineral loss. Rationally designed $\beta$-sheet-forming peptides P114 that self-assemble themselves to form three-dimensional scaffolds under defined environmental conditions have been shown to nucleate hydroxyl apatite de novo and to have potential applications in mineralized tissue regeneration, mimicking the action of enamel matrix proteins during tooth development. ${ }^{(13)}$ 
Egyptian

Orthodontic Journal

Peptide treatment significantly increased net mineral gain due to a combined effect of increased mineral gain and inhibition of mineral loss. In addition, P11-4 in its assembled form was shown to induce hydroxyapatite nucleation de novo. Based upon this data, self-assembling peptides would be useful in the modulation of mineral behaviour during insitu dental tissue engineering. ${ }^{(14)}$

Curodont $^{\mathrm{TM}}$ (Credentis AG, Windisch, Switzerland, distributed by MS Dental AG, Busswil, Switzerland) can be considered an innovative approach; it is a "self-assembling" peptide P11-4. Its approach is to regenerate enamel based on the principle that monomers of this peptide congregate in a three-dimensional network which simulates the enamel matrix. This patented peptide diffuses into an initial lesion and induces the buildup of new hydroxylapatite crystals. This enamel matrix can be regenerated with calcium and phosphate ions from the saliva. This in turn should arrest the initial caries in the long term and trigger natural threedimensional regeneration of the enamel. ${ }^{(15)}$

Aqueous P11-4 in its monomeric form applied to the lesion surface will penetrate in to the pores due to its low viscosity. Self-assembly 'SLE' is triggered by the conditions ( $\mathrm{pH}<7.4$, presence of salts) within the lesion forming fibers, which can nucleate hydroxyapatite mineral. This restores both the enamel mineral and the natural appearance of the original lesion. ${ }^{(13)}$

Because ph is a critical factor in enamel demineralization process, decalcification of enamel adjacent to orthodontic brackets is a dynamic process with periods of demineralization when plaque $\mathrm{PH}$ is low alternating with periods of remineralization as the $\mathrm{PH}$ increases due to the buffering capacity of saliva and the high concentration of calcium present. $^{(16)}$

The aim of the current study was to investigate the effect of commercially available Curodont on enamel surface with white spot lesion after orthodontic treatment. Also assessment of the level of $\mathrm{PH}$ of saliva. 
Egyptian

Orthodontic Journal

\section{MATERIAL AND METHOD}

A total of 14 teeth with white spot lesions in orthodontically treated subjects aged 12 to 22 years were enrolled in this clinical study. All participants were recently finished their treatment with fixed orthodontic appliances in the Department of Orthodontics at the faculty of Dentistry for girls, Al-Azhar University. All patients agreed to participate by signing an informed consent. An ethical committee of the department approved the study.

\section{Curodont application:}

According to manufacture instruction, prior to application of curodont*, the tooth surface needs to be cleaned in order to remove the biofilm and the pellicle and to open the pores to the subsurface lesion. The monomeric peptide can then diffuse through the micropores of the hypermineralised plate into the lesion body.

Recommendations for conditioning and application of curodont; through cleaning of the tooth by a dentist, removal of organic depris and dissolution of the pellicle with $2 \%$ Hypochloride for 20 seconds, removal of inorganic materials and opening the micropores by etching with $35 \%$ phosphoric acid for 20 seconds, rinse the tooth with water, dry the tooth surface. Dissolve curodont in $0.05 \mathrm{ml}$ of $\mathrm{H}_{2} \mathrm{O}$ and apply 1 drop onto the surface of the tooth, wait until the drop disappears or for five minuts.

Digital x-ray assessment: digital periapical x-ray was taken before and after three months of curodont application.

\section{Radiographic Evaluation:}

Standardized reproducible periapical radiographs for each sample were done at baseline and after application of the tested materials. A direct digital image radiographic system; the DBS-win software, which is a part of the Vista Scan system (Durr Dental Bietigheim, Bissingen, Germany) was followed in this study to obtain and calculate pixel gray measurement (enamel mineral content change) using the image processing software. The image plate was exposed to the $\mathrm{x}$-ray machine (Orix-65 mobile x-ray machine, ARDET Srl, Italy) at 70 Kilovolt, $8 \mathrm{~mA}$ for 0.04 seconds. The exposure parameters were fixed for all the samples 
Egyptian

Orthodontic Journal

before and after each treatment. The image plate was inserted into the flat bed scanner and the radiographic image was displaced within seconds on the computer screen and then saved in a digital folder. For each sample, information was saved for each image.

The saved images of each sample were interpreted to evaluate and record the pixel gray measurement (mineral content change). For each sample, two parallel lines were drawn. The two lines were running vertically from the cusp tip to the cemento-enamel junction and each one was starting $2 \mathrm{~mm}$ from the proximolabial or proximolingual line angle either mesially or distally.

The pixel grey level along each line was recorded $1 \mathrm{~mm}$ at the beginning of the line, at the middle, and at the end of the line. The average of the three reading was calculated and recorded to obtain the mean average grey level along this line. The mean value of the readings of the two lines was calculated to present the pixel grey measures of each image. For each sample, a comparison between the measures of the baseline and post treatment images was calculated to determine the radiodenisty change (mineral content change) before and after treatment.

\section{Assessment of saliva PH:}

\section{Saliva sampling:}

Un-stimulated whole saliva specimens were collected in the morning and it was asked from all subjects who brush their teeth and do not use any oral stimulation such as eating and drinking for 90 min prior to collection (Navazesh, 1993). Subjects were in sitting and anterior head protrusion position. Whole saliva samples were obtained by expectorating into polypropylene tubes within 5 min. ${ }^{(23)} \mathrm{pH}$ of saliva samples was determined using a using saliva - check buffer Testing. Saliva-Check Buffer is an examination tool that can be used to educate the patient, assist in the preventive treatment planning, and used to initiate changes in the patient's oral hygiene.

\section{Collection of saliva and its analysis:}

Saliva was collected to measure the change of $\mathrm{pH}$ of saliva every three months, using saliva - check buffer Testing. Saliva-Check Buffer 
Egyptian

Orthodontic Journal

is an examination tool that can be used to educate the patient, assist in the preventive treatment planning, and used to initiate changes in the patient's oral hygiene.

\section{Saliva-Check Buffer Contains:}

In Vitro pH Test Strips (20 pieces), Saliva Dispensing Cups (20 pieces). Wax Gum Pieces for Saliva Stimulation (20 pieces), Saliva Dispensing Pipettes (20 pieces), Buffer Test Strips (20 pieces)

\section{PH test:}

a- Resting saliva was collected before any meals, early in the morning.

b- Subjects were seated and asked to lean forward. Saliva was drooled at 30 -s intervals into a collection plastic cup.

c- $1 \mathrm{ml}$ of the saliva was taken and salivary $\mathrm{pH}$ was determined by $\mathrm{pH}$ indicator.

d- Take the enclosed $\mathrm{pH}$ strip, place one end of it into the sample of resting saliva for 10 seconds and then check the color of the strip.

Highly acidic saliva will be in the red section, $\mathrm{pH} 5.0-5.8$. Moderately acidic saliva will be found in the yellow section, $\mathrm{pH} 6.0$ - 6.6. Healthy saliva will be in the green section $\mathrm{pH} 6.8-7.8$.

e- The results were recorded as the baseline $\mathrm{PH}$ for each patient before the application of the re-mineralizing material. This was repeated every three months during the follow up period.

So, 3 readings were recorded for each patient, a baseline, after 3 months and after 6 months.

\section{RESULTS}

\section{$\underline{\text { Statistical analysis }}$}

Numerical data were explored for normality by checking the data distribution, calculating mean and median values and using KolmogorovSmirnov and Shapiro-Wilk tests. Data showed parametric distribution. Data e represented as mean, standard deviation (SD), median, range and 95\% Confidence interval $(95 \% \mathrm{CI})$ values. 
Egyptian

Orthodontic Journal

Paired t-test was used to compare between enamel mineral content change before and after treatment.

The significance level was set at $\mathrm{P} \leq 0.05$. Statistical analysis was performed with IBM ${ }^{\circledR}$ SPSS $^{\circledR}$ Statistics Version 20 for Windows.

\section{Descriptive statistics}

Descriptive statistics of enamel mineral content change are presented in Table (1).

Table (1): Descriptive statistics of enamel min01eral content change

$95 \% \mathrm{CI}$

\begin{tabular}{lccccccc} 
Time & Mean & SD & Median & Minimum & Maximum & $\begin{array}{r}\text { Lower } \\
\text { bound }\end{array}$ & $\begin{array}{c}\text { Upper } \\
\text { bound }\end{array}$ \\
\hline Pre-treatment & 107.9 & 22.5 & 107.5 & 78.2 & 146.2 & 94.9 & 120.9 \\
3 months & 132.5 & 29.0 & 120.9 & 90.0 & 168.8 & 115.8 & 149.3 \\
\hline
\end{tabular}

\section{Effect of treatment}

There was a statistically significant increase in enamel mineral content after treatment. The mean \pm standard deviation values of percentage increase were $25.7 \pm 16.1 \%$.

Table (2): Mean, standard deviation (SD) values and results of paired t-test for the changes in enamel mineral content change after treatment

\begin{tabular}{|c|c|c|c|c|c|c|}
\hline \multicolumn{2}{|c|}{ Pre-treatment } & \multicolumn{2}{|c|}{3 months } & \multicolumn{2}{|c|}{$\%$ increase } & \multirow{2}{*}{$P$-value } \\
\hline Mean & SD & Mean & SD & Mean & SD & \\
\hline 107.9 & 22.5 & 132.5 & 29.0 & 25.7 & 16.1 & $<0.001 *$ \\
\hline
\end{tabular}

*: Significant at $P \leq 0.05$

Volume 50-December 2016 
Egyptian

Orthodontic Journal

Table (3): $\mathrm{pH}$ change after application of the remineralizing agent within the Curodont group and significance of the difference

\begin{tabular}{|l|c|c|c|}
\hline \multirow{2}{*}{} & \multicolumn{3}{|c|}{ Curodont repair Group } \\
\cline { 2 - 4 } & baseline & After 3months & After 6 months \\
\hline Mean & $6.12^{\mathrm{c}}$ & $6.68^{\mathrm{b}}$ & $7.06^{\mathrm{a}}$ \\
\hline SD & 0.21 & 0.25 & 0.28 \\
\hline Min & 5.80 & 6.20 & 6.60 \\
\hline Max & 6.40 & 7.00 & 7.40 \\
\hline F value & \multicolumn{3}{|c|}{35.6} \\
\hline P value & $<0.0001^{*}$ \\
\hline
\end{tabular}

*: Significant at $P \leq 0.05$

$\mathrm{pH}$ gradually increased by time after application of the re-mineralizing agent.

ANOVA test revealed that the difference was statistically significant $(p<0.0001)$. Tukey's post hoc test revealed a significant difference between each two observation times.

Discussion: In the oral environment, tooth structure undergoes continuous demineralization and remineralization .If this balance is disrupted demineralization will progress. Remineralization may be enhanced by providing low levels of calcium and phosphate, in conjunction with minimal amounts of fluoride. It is truly remarkable the difference that a very small amount of fluoride $(<1 \mathrm{ppm})$ has upon demineralization and remineralization. ${ }^{(17)}$

Certain groups are more apt to present enamel anomalies due to caries (e.g., patients with fixed orthodontic appliances, those with certain diseases or who take medication). Intensive preventive measures, such as the regular use of fluorides, do not always succeed, especially in patients at increased risk of caries. Nonetheless, active initial lesions can be alleviated via the application of fluoride. ${ }^{(18)}$

Diagnosis of incipient noncavitated caries is especially important because if diagnosed at this stage their progression can be prevented and 
the need for future restorative treatments will be eliminated. Therefore in this study we focused on remineralization of these lesions. ${ }^{(19)}$

There is a clear demonstration in the literature that fixed orthodontic appliances increase plaque accumulation, bacterial colonization, and resultant enamel decalcification ${ }^{(20)}$

The aim of the present study was to investigate the efficacy of commercially available Curodont on WSLs after orthodontic treatment.

This study represents the processes occurring during enamel biomineralisation, where a self-assembled organic matrix controls the deposition and growth of hydroxyapatite crystals. As a potential treatment for early caries lesions, P 11 - 4 is safe, non-invasive, and acceptable to patients. ${ }^{(13)}$

The results of 6 months follow-up demonstrate in-depth remineralisation of the lesion after treatment with CurodontTM Repair. Digital subtraction analysis demonstrated increased remineralisation within the subsurface lesions ${ }^{(21)}$

This study showed that there was a statistically significant increase in enamel mineral content after treatment. The mean \pm standard deviation values of percentage increase were $25.7 \pm 16.1 \%$. This is in agreement with another research that evaluated the remineralisation efficacy Curodont Repair in respect to a fluoride varnish in patients with early buccal carious lesion, their results indicated that a superior remineralisation of the white spot lesions for Curodont Repair compared to Duraphat. (22)

A study investigated the efficacy of commercially available Curodont on smooth surfaces. The enamel was checked for signs of remineralization or demineralization after a 12-week remineralization period. They found differences in the measurements between the test and control groups were significant after 8 and 12 weeks, improved remineralization is made possible by providing calcium and phosphate. Curodont presents a new approach in the latter context by inducing the formation of a new enamel matrix to facilitate the incorporation of available calcium and phosphate from the saliva. ${ }^{(18)}$ 
Egyptian

Orthodontic Journal

The level of the salivary $\mathrm{PH}$ in this study was acidic, indicating a strong relation between salivary $\mathrm{PH}$ and presence of enamel surface demineralization and this result agreed with many authors. Singh et al observed that the mean values for $\mathrm{pH}$, buffering capacity, calcium and phosphorous were higher in caries- free group that suggests with the increase in the level of tested parameters. ${ }^{(24)}$

Also Hussien et al found a significant positive correlation between buffering capacity, levels of salivary S. Mutans and caries index. ${ }^{(25)}$

Using commercial kits allows detecting the microbiological caries risk in the daily clinical practice in a practical and fast way, without the need of laboratory procedures ${ }^{(26)}$

There is increase in the salivary $\mathrm{PH}$ after enamel surface treatment with curodont, this may be revealed to the change in the buffering capacity of the saliva.

Conclusion: Based on radiographic evaluation, Curodont proved to be effective as remineralizing agent for treatment of enamel WSLs that occurred after orthodontic treatment, as there is increase in the enamel mineral content after 3 months of curodont treatment. The salivary $\mathrm{PH}$ increased after 3 and 6 months of curodont application.

\section{REFERENCES}

1- Deyhle H, Dziadowiec I, Kind L, Thalmann P Schulz G and Müller B ; Mineralization of Early Stage Carious Lesions In Vitro-A Quantitative Approach. Dent. J. 2015;3:111-122.

2- Bishara SE, Ostby AW. White spot lesions: formation, prevention, and treatment. Semin Orthod 2008; 14:174-82.

3- Chang HS, Walsh LJ, Freer TJ. Enamel demineralization during orthodontic treatment. Aetiology and prevention. Aust Dent J 1997; 42:322-7.

4- Ogaard B, Larsson E, Henriksson T, Birkhed D, Bishara SE. Effects of combined application of antimicrobial and fluoride varnishes in orthodontic patients. Am J Orthod Dentofacial Orthop 2001;120: 28-35. 
Egyptian

Orthodontic Journal

5- Ogaard B, Rolla G, Arends J, ten Cate JM. Orthodontic appliances and enamel demineralization. Part 2. Prevention and treatment of lesions. Am J Orthod Dentofacial Orthop 1988;94:123-8.

6- Shungin D, Olsson AI, Persson M. Orthodontic treatment-related white spot lesions: a 14-year prospective quantitative follow-up, including bonding material assessment. Am J Orthod Dentofacial Orthop 2010;138:136-7.

7- Jablonski-Momeni A., Heinzel-Gutenbrunner M. Efficacy of the selfassembling peptide P11-4 in constructing a remineralization scaffold on artificially-induced enamel lesions on smooth surfaces. J Orofac Orthop 2014; 75:175-190

8- Willmot D. White Spot Lesions After Orthodontic Treatment. Semin Orthod 2008; 14:209-219.

9- Poggio C , Ceci M, Beltrami R, Lombardini M, Colombo M, Atomic force microscopy study of enamel remineralization Annali di Stomatologia 2014; 3: 98-102

10- Jayasudha, Baswara j, Navin H.K, and Prasanna K.B. Enamel Regeneration - Current Progress and Challenges.Journal of Clinical and Diagnostic Research. Sep; 2014:Vol-8(9):6-9.

11- Chen H, Liu X, Dai J, Jiang Z, Guo T, and Ding Y. Effect of remineralizing agents on white spot lesions after orthodontic treatment: A systematic Review. Am j orthod dentofacial orthoped, 2013; 143:376-82.

12- Naveena Preethi P, Nagarathana $C$ and Sakunthala BK. Remineralizing Agent -Then and Now. An Update. Dentistry 2014; 4:9.

13- Brunton PA, Davies RP, Burke JL, Smith A, Aggeli A, Brookes SJ, Kirkham J. Treatment of early caries lesions using self assembling peptides- A clinical safty trial. British dental journal 2013; 215:e6.1-6.

14- Kirkham J., Firth A, Vernals D., Boden N., Robinson C., Shore R.C, Brookes S.J, and Aggeli A. Self-assembling peptide scaffolds promote enamel remineralization. J Dent Res 2007;86:426-430. 
15- Silverstone LU, Wefel JS, Zimmerman BF, Clarkson BH and Featherstone MJ. Remineralization of natural and artificial lesions in human dental enamel in vitro. Caries Res J 1981; 15:138-157.

16- Nikneshan S, Abbas F and Sabbagh S; Detection of proximal caries using digital radiographic systems with different resolutions. Indian Journal of Dental Research 2015; 26: 5-10.

17- Hicks J1, Garcia-Godoy F, Flaitz C. Biological factors in dental caries: role of remineralization and fluoride in the dynamic process of demineralization and remineralization (part 3). J Clin Pediatr Dent. 200;28:203-14

18- Jablonski-Momeni A M. Heinzel-Gutenbrunner. Efficacy of the self-assembling peptide P11-4 in constructing a remineralization scaffold on artificially induced enamel lesions on smooth surfaces. Journal of Orofacial Orthopedics. May 2014, Volume 75, Issue 3, pp $175-190$

19- Hans Deyhle, Iwona Dziadowiec, Lucy Kind, Peter Thalmann, Georg Schulz, and Bert Mülle. Mineralization of Early Stage Carious Lesions In Vitro-A Quantitative Approach. Dent. J. 2015;3: $111-122 J$

20- Suchita S. Daokar, Handa Amit Satish, Sunita Sachdeo. Time to Rethink. Journal of Dental and Medical Sciences. 2013;3:14-19

21- Schlee M, Rathe F, Huck T, Schad T, Koch J.H, Tjaden A and Bommer C. Clinical Effect of biomimetic mineralization in approximal caries. Results of a clinical study after 6 months. Curodont Repair in Patients with Proximal Carious Lesions: Uncontrolled, Non-Interventional Study-intermediate report. Stomatologie 2014; 111:175-181.

22- Broseler F., Tietmann C., Schleich R., Drechsel T. and Bommer C. Effect of Curodont ${ }^{\mathrm{TM}}$ Repair in Patients with Buccal Carious Lesions: A Mono-centre, Single-blinded, Randomised, Controlled Split-mouth Study - intermediate report.2013. Conseuro - 2013-Poster. Clin Oral Invest. 2013;9-1111. 
Egyptian

Orthodontic Journal

23- Ahmadi-Motamayel F., Goodarzi M. T., Hendi S. S., Abdolsamadi H. and Rafieian N. Evaluation of salivary flow rate, $\mathrm{pH}$, buffering capacity, calcium and total protein levels in caries free and caries active adolescence. Journal of Dentistry and Oral Hygiene 2013; 4:35-39.

24- Singh S, Sharma A, Sood P.B, Sood A, Zaidi I, and Sinha A. Saliva as a prediction tool for dental caries: An in vivo study:sêp. Journal of oral biology and craniofacial research. 2015;5:59-64.

25- Hussein N., Bhaskar S and Al-Radaideh A. Caries Risk Assessment in Children using Salivary Parameters. International Journal of Advanced Dental Science and Technology 2014; 1:25-34.

26- Saravia M., Silva L., Silva R., Lucisano M. , Echevarría A. , Uribe Echevarría J., Nelson-Filho P. Evaluation of Chair-Side Assays in High Microbiological Caries-Risk Subjects. Braz. Dent. J. 2015;6:592-595 